Bangl. J. Vet. Med. (2006). 4 (1): 13-18

\title{
GASTROINTESTINAL HELMINTHS INFECTION IN DIFFERENT TYPES OF POULTRY
}

\author{
A. K. M. A. Rabbi ${ }^{*}$, A. Islam, S. Majumder ${ }^{1}$, Anisuzzaman and M. H. Rahman \\ Department of Parasitology, Faculty of Veterinary Science, ${ }^{1}$ Department of Agricultural Statistics, Faculty of \\ Agricultural Economics and Rural Sociology, Bangladesh Agricultural University, Mymensingh-2202, \\ Bangladesh \\ *Corresponding author’s e-mail address: vpara_payel@yahoo.comT
}

\begin{abstract}
The prevalence of gastrointestinal helminth parasites and the gross pathological lesions produced by them in different types of poultry were studied from March 2005 to March 2006, in the Department of Parasitology, Bangladesh Agricultural University, Mymensingh. In this study, 240 viscera of three types of poultry such as broiler, layer and backyard indigenous chickens were collected from local markets of Mymensingh district. During routine examination, total six species of helminth parasites were recorded, of which three species were nematodes such as Ascaridia galli, Heterakis gallinarum and Capillaria annulata; two species were cestodes such as Raillietina tetragona and Amoebotaenia sphenoides and only one species was belonged to trematode such as Catatropis verrucosa. Prevalence of different species of gastrointestinal helminths was highest in backyard poultry (100\%) followed by layer (48.75\%) and broiler $(3.75 \%)$ which was statistically significant $(\mathrm{p}<0.01)$. Backyard poultry was significantly $(\mathrm{p}<0.05) 168.21$ and 4106.67 times more susceptible to helminth infection than layer and broiler respectively. But layer was 24.41 times more susceptible to helminth infection than broiler. In backyard poultry, all six species of helminth parasites were found. A statistically significant $(\mathrm{p}<0.05)$ variation in the prevalence of the recovered parasites from backyard poultry were observed such as the prevalence of $R$. tetragona (100\%) was the highest followed by that of A. galli (87.50\%) and $H$. gallinarum (80\%). From the odds ratio of the recovered parasites, it was observed that chance of developing $R$. tetragona (odds ratio 189.73) in backyard poultry was the highest followed by A. galli (odds ratio 7.51) and H. gallinarum (odds ratio 4.04). In case of layer, only $A$. galli and $R$. tetragona were recorded, of which, prevalence of $A$. galli was the highest (43.75\%). In broiler, only A. galli (3.75\%) was found. Gross pathological lesions were found only in backyard poultry. Pathological changes were detected in case of $A$. sphenoides and H. gallinarum infection. In A. sphenoides infection petechial hemorrhages were observed in the mucosa of the duodenum. On the other hand, tiny, white, circumscribed nodules of about 2-3 mm of diameter were found in the caecal mucosa in case of $H$. gallinarum infection. Results of the present study suggest that the backyard poultry is at the high risk of helminth infection. However, layers are also vulnerable to parasitic infection. So regular deworming is essential both in backyard poultry and layer birds to obtain better production from them.
\end{abstract}

Key words: Gastrointestinal helminths, prevalence, pathology, broiler, layer, backyard poultry

\section{INTRODUCTION}

Poultry is a promising sector in Bangladesh which is increasing day by day. Poultry meat and eggs contribute approximately 37\% of total animal protein in Bangladesh (Ahmed and Islam, 1990). In Bangladesh, different types of poultry are reared such as backyard poultry, broiler and layer. Broiler and layer are mostly reared in organized farms. Backyard poultry is popular among rural people. But the poultry production is hindered by many problems among which various diseases namely bacterial, viral and parasitic infections are the most important (Ojok, 1993). In fact poultry of Bangladesh are parasitized by various parasites (Sarkar, 1976).

A review of literature indicates that very few studies have been undertaken to determine the susceptibility of poultry towards the helminth infection. Besides very little attention has been paid to study the pathology produced by helminth parasites in poultry. By considering these points, the present research work was conducted to determine the prevalence of gastrointestinal helminths in backyard poultry, broiler and layer and also to study the gross pathological lesions produced by them. 


\section{MATERIALS AND METHODS}

This study was conducted from March 2005 to March 2006 to determine the prevalence of gastrointestinal helminths infection in poultry and gross pathological lesions produced by them, in the Department of Parasitology, Bangladesh Agricultural University, Mymensingh. Viscera of 240 poultry were collected from different local markets of Mymensingh district. This study included three types of poultry such as commercial broiler which was reared in deep litter system, culled layer which was reared at first in deep litter system then in cage system and backyard poultry which was reared in semi scavenging system.

After collection, each of the gastrointestinal tracts was examined thoroughly from the outer surface, to detect the gross pathological changes, if any. Therefore, the gastrointestinal tract was subjected to routine examination to collect the gastrointestinal parasites, according to the procedure as described by Fowler (1990). Internal surface of the intestinal tracts was also investigated thoroughly to detect the gross pathological changes, if any. The gross pathological changes were recorded carefully. From the suspected viscera, mucosal scraping was taken and examined under microscope at $10 \mathrm{X}$ magnification by adding a drop of normal saline, mounting with a cover slip to detect tiny parasites which deeply burrow into the mucosa, if any.

Parasites of the intestinal tract were separated from the intestinal content by repeated sedimentation and made clear by gentle washing with PBS. After washing, nematodes were collected by the help of curved needle and kept in glycerin alcohol. Cestodes and trematodes were collected by the help of dropper and preserved in $10 \%$ formalin for the identification. Thorough morphological study of nematodes was performed by the preparation of sub-permanent slide by adding one drop of lactophenol. Morphology of trematodes and cestodes were studied by preparing permanent slide according the methods as described by Cable (1957).

Parasites were identified according to the keys and description given by Soulsby (1982) and Yamaguti (1958).

\section{Statistical analysis}

The prevalence of the different parasitic infection was computed using the formula as descried by Thrusfield (1995). Odds ratio and confidence interval were obtained by the formula according to the Schlesselman (1982).

\section{RESULTS AND DISCUSSION}

\section{Study of prevalence}

The present study revealed that $50.83 \%$ among all poultry examined were infected by one or more species of helminth parasites (Table. 4). Total six species of helminth parasites were recorded of which three species were nematodes, two species were cestodes and one species belonged to trematode (Table 1). Similar studies were conducted by earlier scientists. Wakelin (1964) in Britain found 59.2\%, Romanenko et al. (1985) in Roostov recorded 100\% and Guclu (1994) in Turkey found 59\% birds affected with helminth parasites. But the disparity in between the result of the present and earlier works in other countries might be due to the variation among the geographical location of the research area, method of study and sample size.

Table 1. Parasites recovered from different types of poultry

\begin{tabular}{|lll|}
\hline Class of parasites & Name & Location \\
\hline Nematoda & Ascaridia galli Schrank, 1788 & Small intestine \\
& Heterakis gallinarum Schrank, 1788 & Caecum \\
& Capillaria annulata Molin, 1858 & Caecum \\
Cestoda & Raillietina tetragona Molin, 1858 & Small intestine \\
& Amoebotaenia sphenoides Railliet, 1892 & Duodenum \\
Trematoda & Catatropis verrucosa Froelich, 1789 & Caecum \\
& & \\
\hline
\end{tabular}


Helminths infection in poultry

Table 2. Prevalence of parasitic infections in broiler and layer

\begin{tabular}{|c|c|c|c|c|c|}
\hline \multirow[t]{3}{*}{ Class } & \multirow[t]{3}{*}{ Name of the Parasites } & \multicolumn{4}{|c|}{ Prevalence } \\
\hline & & \multicolumn{2}{|c|}{ Broiler $(\mathrm{n}=80)$} & \multicolumn{2}{|c|}{ Layer $(\mathrm{n}=80)$} \\
\hline & & No. & $\%$ & No. & $\%$ \\
\hline \multirow[t]{3}{*}{ Nematode } & A. galli & 3 & 3.75 & 35 & 43.75 \\
\hline & Heterakis gallinarum & 0 & 0 & 0 & 0 \\
\hline & Capillaria annulata & 0 & 0 & 0 & 0 \\
\hline \multirow[t]{2}{*}{ Cestode } & Raillietina tetragona & 0 & 0 & 13 & 16.25 \\
\hline & Amoebotaenia sphenoides & 0 & 0 & 0 & 0 \\
\hline Trematode & Catatropis verrucosa & 0 & 0 & 0 & 0 \\
\hline
\end{tabular}

$\mathrm{n}=$ Number of birds examined.

Table 3. Prevalence of parasitic infections in backyard poultry

\begin{tabular}{|llllll|}
\hline \multirow{2}{*}{ Class } & Name of parasites & \multicolumn{2}{l}{ Prevalence $(\mathrm{n}=80)$} & \multirow{2}{*}{ Odds ratio } & \multirow{2}{*}{$95 \%$ confidence interval } \\
\cline { 3 - 4 } & & No. & $\%$ & & \\
\hline Nematode & Ascaridia galli & 70 & 87.50 & 7.51 & $3.76-14.99$ \\
& Heterakis gallinarum & 64 & 80.0 & 4.04 & $2.26-7.23$ \\
& Capillaria annulata & 04 & 5.00 & 0.03 & $0.002-0.08$ \\
Cestode & Raillietina tetragona & 80 & 100.00 & 189.73 & $11.68-3081.15$ \\
& Amoebotaenia sphenoides & 32 & 40.00 & 0.49 & $0.30-0.80$ \\
Trematode & Catatropis verrucosa & 13 & 16.25 & 0.12 & $0.06-0.22$ \\
\hline
\end{tabular}

$\mathrm{n}=$ Number of birds examined.

Table 4. Susceptibility of different types of poultry to gastrointestinal helminthes

\begin{tabular}{|c|c|c|c|c|c|}
\hline \multirow[t]{2}{*}{ Type of poultry } & \multicolumn{2}{|c|}{ Prevalence $(n=80)$} & \multicolumn{2}{|c|}{ Odds ratio } & \multirow[t]{2}{*}{ 95\% Confidence interva } \\
\hline & No. & $\%$ & & & \\
\hline Backyard poultry (BP) & 80 & $100 * *$ & $\begin{array}{l}\text { BP vs B } \\
\text { BP vs L }\end{array}$ & $\begin{array}{l}4106.67^{*} \\
168.21^{*}\end{array}$ & $\begin{array}{l}202.36-83335.15 \\
10.08-2807.57\end{array}$ \\
\hline $\begin{array}{l}\text { Broiler (B) } \\
\text { Layer (L) }\end{array}$ & $\begin{array}{l}03 \\
39\end{array}$ & $\begin{array}{l}3.75^{* *} \\
48.75^{* *}\end{array}$ & L vs B & $24.41 *$ & $7.11-83.84$ \\
\hline Overall & 122 & 50.83 & - & - & - \\
\hline
\end{tabular}

$\mathrm{n}=$ Number of birds examined, ** indicates significant at $\mathrm{p}<0.01$, * indicates significant at $\mathrm{p}<0.05$. 
It was observed that among three types of poultry, infection rate was highest in backyard poultry (100\%) followed by layer $(48.75 \%)$ and broiler $(3.75 \%)$. This variation was statistically significant $(\mathrm{p}<0.01)$. Backyard poultry was significantly ( $<$ 0.05) 168.21 and 4106.67 times more susceptible to helminth infection than that of layer and broiler respectively. But layer was 24.41 times more susceptible to helminth infection than that of broiler (Table. 4). Similar studies were also performed by earlier scientists (Ssenyonga, 1982; Kang and Suh, 1987; Samad and Rahman, 1985; Huq, 1986). Backyard poultry of Bangladesh are reared in semi-scavenging system, in which they collect maximum of their food from the nature. Their food enterprise includes different types of seeds, kitchen wastages, insects, slugs, earthworm etc. Insects, slugs, earthworm etc. act as intermediate or paratenic hosts of many bio-parasites (Soulsby, 1982). Besides, backyard poultry can easily ingest the infective stage of many geo-parasites during taking food from the environment. Probably for the above mentioned causes backyard poultry is more susceptible to helminth infection. On the other hand, layer, at first reared in deep litter system then in cage system. So there is a chance of gaining infection in their first life which may continue up to the last stage of life. But there is less chance of infection in their cage life. In case of broiler, chance of gaining infection is very low as they are reared in intensive system maintaining a strict hygienic measure. Moreover, the life span of broiler is very short ranging usually from 35 to 45 days. This very short period of time is not enough to complete the life cycle of maximum helminth parasites.

In backyard poultry all six species of helminth parasites were found. Among them prevalence of $R$. tetragona was the highest (100\%) followed by A. galli (87.50\%) and H. gallinarum (80\%). Odds ratio of these above three parasites were statistically significant $(\mathrm{p}<0.05)$. The prevalence of $C$. annulata $(5 \%)$ was the lowest. The odds ratio 7.51 indicated that backyard were 7.51 times more likely to be infected by A. galli than other parasites. By the odds ratio 4.04 it can be concluded that the risk of being infected by $H$. gallinarum of backyard poultry was 4.04 times more than the other parasites. The odds ratio of $R$. tetragona was 189.73 implies that the risk of developing $R$. tetragona in backyard poultry was the highest (Table 3). In backyard poultry, almost same types of investigations were performed by some scientists (Samad and Rahman, 1985; Huq, 1986). But the differences in between the results of present and previous authors might be due to the variation in the method of study, sample size and ecological pattern. In case of R. tetragona, ant of the genera Tetramorium, Pheidole and house fly, Musca domestica act as intermediate host which are very much available in our country, especially in the rural areas. Backyard poultry are very fond of scavenging various insects from the nature. Probably for this reason prevalence of $R$. tetragona was the highest in backyard poultry. Similarly, earthworm, the paratenic host of A. galli and H. gallinarum is also available in Bangladesh. It is also a favourite food item of poultry.

In layer birds, only A. galli and R. tetragona were recorded, in between them, prevalence of A. galli was the highest (43.75\%) (Table 2). Eggs of A. galli are resistant to common disinfectants and they can maintain a direct life cycle without the help of earthworm (Soulsby, 1982). But the $R$. tetragona can not complete their life cycle without the help of invertebrate host like ant and house fly (Permin and Hansen, 1998). So, the chance of infection with $A$. galli is relatively higher in commercial farming.

\section{Gross pathological lesion}

During the present study, pathological lesions were found only in backyard poultry. Pathological changes were produced by $A$. sphenoides and $H$. gallinarum. In case of $A$. sphenoides gross pathological changes included petecheal haemorrhages in the duodenum (Fig. 1).

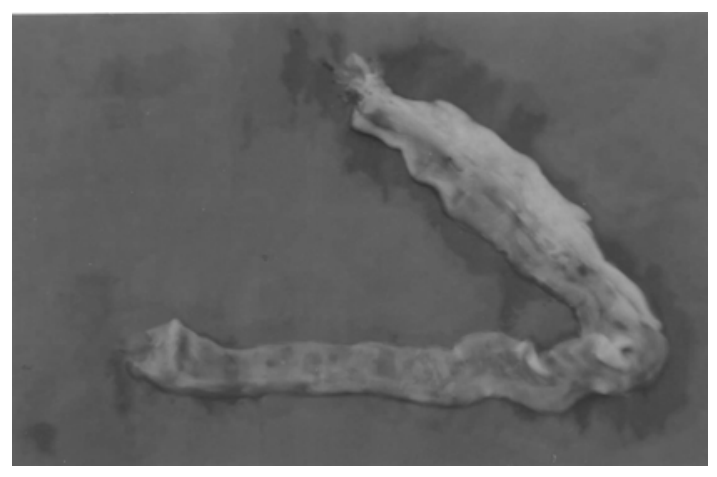

Fig. 1. Petechial haemorrhages in duodenum of backyard poultry due to $A$. sphenoides infection. 


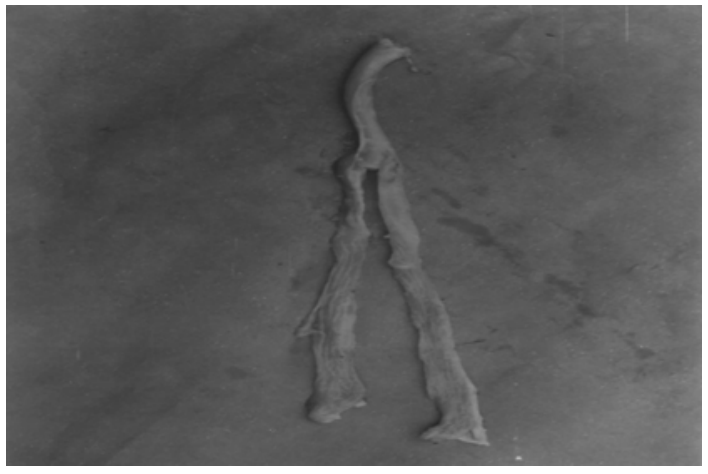

Fig. 2. Nodule in the caecum of backyard poultry due to $H$. gallinarum infection.

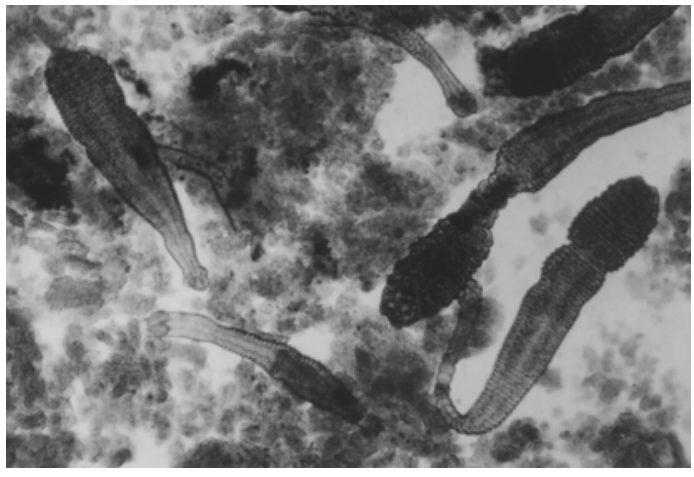

Fig. 3. A. sphenoides in duodenal scrapping (10X).

Large numbers of parasites were found during the microscopic study of mucosal scraping of affected duodenum (Fig. 3). Compare and contrast of the result of present study can not be made due to paucity of relevant literature. The exact mechanism of petechial haemorrharge is not known. However, the parasite, probably penetrate deeply into the mucosa. During penetration, large number of parasites set up petechial haemorrhage. In case of $H$. gallinarum, white, small sized (approximately two to three mm in diameter) nodules were found in the caecal mucosa (Fig. 2). Similar types of lesions were recorded by Kaushik and Deorani (1969). Probably marked inflammatory reaction in the mucosa of caecum leads to the development of nodule.

In conclusion, it can be said that backyard poultry is in the high risk of helminth infection. However, layer birds are also not free from the risk of infection. Moreover, the parasites are associated with the development of pathological changes. Therefore, they have economic impact in the poultry production. So, proper deworming programme should be conducted.

\section{REFERENCES}

1. Ahmed S and Islam N (1990). Backyard poultry development project in 100 villages. Proceeding of the $1^{\text {st }}$ Conference of Bangladesh Animal Husbandry Association. Feb. 23-24, 1985, Bangladesh Agricultural Research Council, Dhaka, Bangladesh. pp. 13-138.

2. Cable RM (1957). An Illustrated Laboratory Manual of Parasitology, $4^{\text {th }}$ edn., Burgess Publishing Co., 426, South Sixth Street, Minneapolis 15, Minnesota.

3. Fowler NG (1990). How to carry out a field Investigation In: Poultry Diseases, F. T.W. (2 ${ }^{\text {nd }}$ edn.,.) Bailliere Tindall, Londal, pp. 370-400.

4. Guclu F (1994). Helminth fauna of fowls, turkeys, ducks and geese in the Ankara area. Doga,-Turk-Veterinarlik-VcHyavncilik-Dorgisi 18: 79-86.

5. Huq, MS (1986). Studies on the helminth infections of poultry under rural conditions of Bangladesh. Bangladesh Veterinary Journal 20: 55-60.

6. Kang YB and Suh MS (1987). Efficacy of febantel against Ascaridia galli and other important nematodes in laying hens in relation to their productivity. Korean Journal of Veterinary Public Health 11: 33-38.

7. Kaushik RK and Deorani VPS (1969). Studies on tissue responses in primary and subsequent infection with Heterakis gallinarum in chickens and on the process of formation of caecal nodules. Journal of Helminthology 43: 69-78.

8. Ojok L (1993). Diseases as important factor affecting increased poultry production in Uganda. Der Tropenland Wirt Zeitschrift fur die landwirtschaft in din Tropen and Subtropen 94: 37-44.

9. Permin A and Hansen JW (1998). Epidemiology, Diagnosis and Control of Poultry Parasites. Food and Agricultural Organization of the United Nations, Rome.

10. Romanenko PT, Troenko YAIA and Kuzyakin AV (1985). Age variation in helminth infection on chickens farm and factors farms in the Roostov region. Nahrung 29: 304-310.

11. Samad MA and Rahman A (1985). Incidence of gastrointestinal parasitic infection in domestic fowls of Bangladesh. Poultry Adviser 18: 33-38. 
12. Sarkar AJ (1976). The prevalence of avian diseases in Bangladesh Agricultural University Farm. Bangladesh Veterinary Journal 10: 61-66.

13. Schlesselman JJ (1982). Case Control Studies. Oxford University Press, $2^{\text {nd }}$ edn., New York, USA. pp.174-177.

14. Soulsby EJL (1982). Helminths, Arthropods and Protozoa of Domesticated Animals. $7^{\text {th }}$ edn., Bailliere Tindall and Cassell Ltd. London.

15. Ssenyonga GSZ (1982). Prevalence of helminth parasites of domestic fowl in Uganda. Tropical Animal Health and Production 14: 201-204.

16. Thrusfield M (1995). Veterinary Epidemiology. $2^{\text {nd }}$ edn., Blackwell Science, USA. pp. 39-41.

17. Wakelin D (1964). A survey of the intestinal helminth parasites in British domestic fowls. Journal of Helminthology 38: 191-200.

18. Yamaguti S (1958). Systema Hilminthum. Vol. I, II, III and V, Intersience Publishers, Inc. New York, USA. 